\title{
Crohn's disease with pulmonary granuloma in a child: a case report and review of the literature
}

\author{
Wei Cao ${ }^{\#}$, Xing Deng", Chundi Xu, Xinqiong Wang, Yi Yu, Xu Xu, Jia Li, Yuan Xiao \\ Department of Pediatrics, Ruijin Hospital, Shanghai Jiao Tong University, School of Medicine, Shanghai, China \\ "These authors contributed equally to this work. \\ Correspondence to: Yuan Xiao. Department of Pediatrics, Ruijin Hospital, Shanghai Jiao Tong University, School of Medicine, 197, Rui Jin Er Road, \\ Huangpu District, Shanghai 200025, China. Email: xy11438@rjh.com.cn.
}

\begin{abstract}
Crohn's disease (CD) is a chronic granulomatous disease that affects the gastrointestinal system. Additionally, CD has multiple extraintestinal manifestations, and bronchopulmonary manifestations are extremely rare. Pulmonary lesions can occur before the diagnosis of CD; thus, pulmonary manifestations are often overlooked, which leads to misdiagnoses. Herein, we present a case with pulmonary nodules being exhibited before the patient was diagnosed with CD. To the best of our knowledge, only a few cases concerning this phenomenon have been reported. We describe an 11-year-old boy with a two-year history of anemia and without any gastrointestinal symptoms. He did not receive any thorough inspection until arthralgia occurred. Multiple nodules were found in his bilateral lungs via computed tomography scan. Combined with the child's medical history, physical examinations, and all of the investigations, the final diagnosis was CD with pulmonary nodules and arthritis. After 2 months of treatment, the patient's symptoms had significantly improved. To summarize the clinical manifestations, auxiliary examination features, and treatments of CD in children with pulmonary involvement, we also review the relevant characteristics of pulmonary involvement in CD patients. This case indicates the importance of recognizing the pulmonary manifestations of CD. Clinicians should be aware of the possibility of CD when their patients have lung nodules, even in children with no typical manifestations of CD.
\end{abstract}

Keywords: Crohn's disease (CD); pulmonary; children; case report

Submitted Jan 29, 2021. Accepted for publication Apr 20, 2021.

doi: $10.21037 / \mathrm{tp}-21-41$

View this article at: http://dx.doi.org/10.21037/tp-21-41

\section{Introduction}

Crohn's disease (CD) is a complex, multifactorial disease that is characterized by chronic inflammation of the gastrointestinal system (1). It may affect any part of the gastrointestinal tract from the mouth to the anus. Approximately $25-40 \%$ of patients with CD can have multiple extraintestinal manifestations, including erythema nodosum, pyoderma gangrenosum, ankylosing spondylitis, arthritis, hepatitis, sclerosing cholangitis, pancreatitis, nephrolithiasis, uveitis, and episcleritis (2). The first report of lung involvement in CD was published in 1976 (3). The bronchopulmonary manifestations of CD are very rare extraintestinal manifestations, and the literature reports that the prevalence of these manifestations is as low as $0.2 \%$ (4). However, this prevalence rate may be underestimated, as an increasing number of cases have reported that the pulmonary performance of adult CD patients may be higher than was previously thought. Reports of children with CD involving the lungs are even rarer; thus, lung lesions are often overlooked. This article reports of one pediatric $\mathrm{CD}$ patient presenting with pulmonary involvement in

^ ORCID: 0000-0002-4737-0880. 
Table 1 Laboratories of our patient

\begin{tabular}{lccc}
\hline & Before treatment & 2 weeks after treatment & 2 months after treatment \\
\hline White blood cell, $10^{9} / \mathrm{L}$ & 10.97 & 20.48 & 10.82 \\
Platelets, $10^{9} / \mathrm{L}$ & 343 & 360 & 215 \\
Hemoglobin, g/L & 101 & 116 & 122 \\
C reactive protein, $\mathrm{mg} / \mathrm{L}$ & 54.3 & 1 & 16.4 \\
ESR, $\mathrm{mm} / \mathrm{h}$ & 38 & 6 & 13 \\
Serum albumin, $\mathrm{g} / \mathrm{L}$ & 35 & - & 38 \\
\hline
\end{tabular}

ESR, erythrocyte sedimentation rate; - , not obtained.

Ruijin Hospital, Shanghai Jiao Tong University School of Medicine in August 2016; additionally, this article reviews the relevant characteristics of pulmonary involvement in CD patients.

We present the following case in accordance with the CARE reporting checklist (available at http://dx.doi. org/10.21037/tp-21-41).

\section{Case presentation}

An 11-year-old male was admitted to our hospital in August 2016 with a 2-year history of anemia, a one-year history of skin purpura, and a four-month history of arthralgia. The child appeared pale and had a decreased appetite without obvious incentives for two years. He was diagnosed in the local hospital with "small cell hypochromic anemia". Irregular oral iron therapy was used for one year, and this anemia treatment was not effective. One year ago, the skin purpura of both feet appeared, which did not fade and gradually spread to the elbows and knees. Four months before admission, there was pain and swelling in the knee and ankle joints of the patient. During the course of the disease, there was no fever, abdominal pain, diarrhea, bloody stools, or other discomforts, but there was decreased appetite and a weight loss of $5 \mathrm{~kg}$ in the patient. There was no significant past medical or family history.

His vital signs on admission were as follows: temperature of $37.2^{\circ} \mathrm{C}$; pulse of 97 beats per minute; respiratory rate of 22 breaths per minute; and blood pressure of 99/64 $\mathrm{mmHg}$. His weight was $25 \mathrm{~kg}$ (below the $3 \mathrm{rd}$ percentile), and his height was $146 \mathrm{~cm}$ (appropriate for his age). He had a pale appearance and an emaciated body. Scattered skin purpura could be observed on the right elbow joint and both lower limbs. It did not fade when pressed, it did not rise above the skin surface, and the patient had no tenderness. There was no jaundice and no superficial lymphadenopathy. His lungs also sounded clear. Bilateral knee and ankle joints were swollen, but the skin temperature was normal, and the bilateral ankle joints were tender.

His laboratory tests after admission showed slightly increased white blood cell and platelet counts in the peripheral blood (Table 1). His hemoglobin was $101 \mathrm{~g} / \mathrm{L}$, hematocrit was $32.8 \%$, serum iron was $5 \mu \mathrm{mol} / \mathrm{L}$, transferin saturation was $9.9 \%$, total iron binding capacity was $50.3 \mu \mathrm{mol} / \mathrm{L}$, and serum ferritin was $44.8 \mathrm{ng} / \mathrm{mL}$. The erythrocyte sedimentation rate was $38 \mathrm{~mm} / \mathrm{h}$, C reactive protein was $54.3 \mathrm{mg} / \mathrm{L}$, and serum albumin was $35 \mathrm{~g} / \mathrm{L}$ (Table 1). His liver function, renal function, and serum electrolytes were normal. Rheumatoid factor, antinuclear antibody, extractable nuclear antigens, anti-neutrophil cytoplasmic antibodies (ANCAs), and HLA-B27 were negative. Both humoral and cellular immune functions were normal. A stool examination was normal, except for a positive result in the fecal occult blood test. Cultures of blood, stool, and urine did not show any signs of infection. Magnetic resonance imaging (MRI) of the knee and ankle revealed effusion of the joint and thickening of the synovium. Gastroduodenoscopy showed a bamboo joint-like appearance (Figure 1A) in his gastric body, and colonoscopy showed mucosal erosion inflammation of the ileocecal region (Figure 1B). The pathology reports of the mucosal biopsies of the gastric body, the terminal ileum, and the other parts of the colon showed signs of chronic inflammation and slight eosinophilic infiltration. Eosinophils were less than 10/ HPF, and $H$. pylori cultures were also negative. MRI of the small bowel was perfected and showed that the terminal ileum was thickened and had inflammation. Multiple nodules were found bilaterally in the lungs via computed tomography (CT). The largest one was measured at 

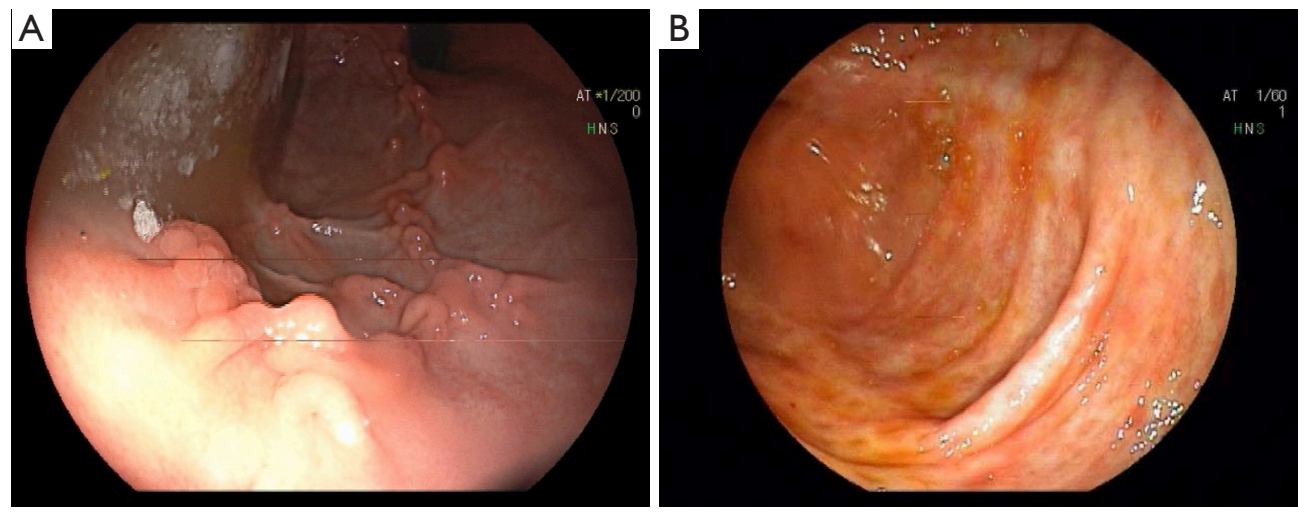

Figure 1 Endoscopy photographs of the patient reported in this case. (A) Gastroscopy image of the patient showing a bamboo joint-like appearance. (B) Colonoscopy image of the patient showing mucosal erosion inflammation of the ileocecal region.
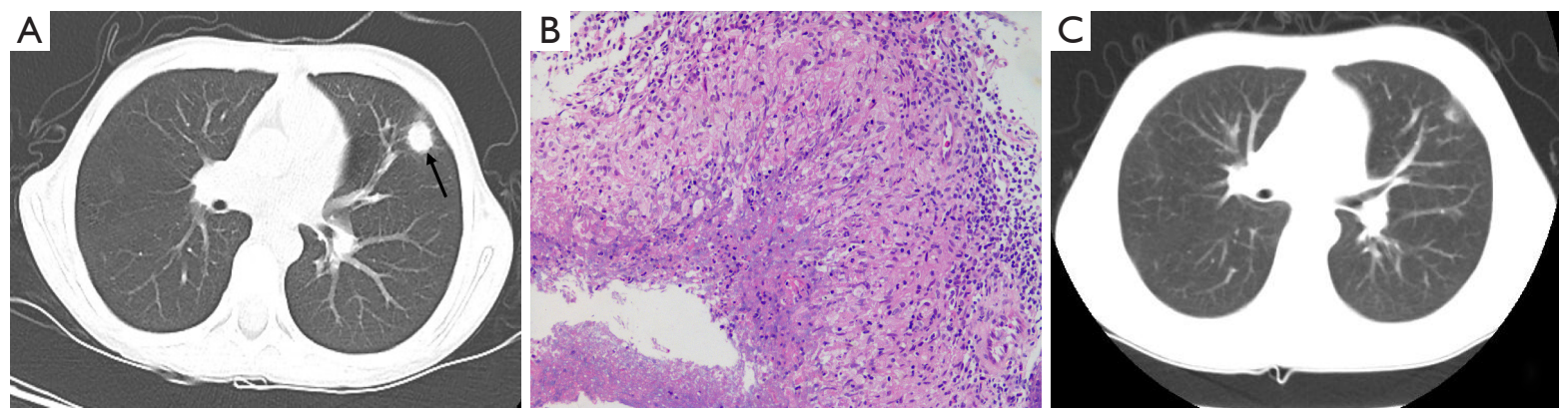

Figure 2 CT photograph of the chest and pathology photograph of the lung nodule in this case. (A) CT scan of the chest after the patient's first admission revealed nodules in the lungs, and the largest nodule is shown by an arrow. (B) Lung nodule biopsy specimen pathology (hematoxylin and eosin, $\times 200$ ) showing coagulation necrosis, epithelial-like cell hyperplasia around the necrosis, and infiltration of lymphocytes and plasma cells in the surrounding tissue, which indicates the granulomatous lesion. (C) CT scan of chest reviewed after 2 months.

$1.39 \mathrm{~cm} \times 1.29 \mathrm{~cm}$ and was located in the upper lobe of the left lung (Figure 2A). However, infectious pathogens, including tuberculosis, aspergillus, legionella, mycoplasma, and chlamydia, were negative. Pulmonary function tests (PFTs) showed severe mixed pulmonary ventilatory dysfunction and moderately decreased pulmonary diffusion function (Table 2). The nodule biopsy was performed via a CT-guided lung puncture. The pathology revealed signs of non-caseating granulomatous lesions, such as focal coagulative necrosis, epithelioid-like cell hyperplasia, and infiltration of lymphocytes and plasma cells in the surrounding tissue (Figure 2B). The biopsy specimens were sent for bacterial, fungal, and mycobacterial analyses, as well as for a cytology analysis. The results showed a large amount of necrosis and a small number of lymphocytes, without cancer cells and infections. A tuberculosis interferon-gamma release assay was conducted, and the result was negative.

Although the patient had no gastrointestinal symptoms, he had gastrointestinal lesions, based on the patient's gastrointestinal endoscopy. This patient had a variety of extraintestinal manifestations, and his pulmonary function was indicated as restrictive pulmonary ventilation dysfunction, which is also very common in CD. The pathology of the pulmonary nodules in the child showed non-caseating granulomatous lesions, and we also ruled out common diseases that cause pulmonary nodules, such as infection, drug induction, sarcoidosis, chronic granulomatous diseases, and Wegener's granulation. After treatment with glucocorticoids, his clinical manifestations, laboratory investigations, pulmonary function, and radiological manifestations had significantly improved. 
Table 2 Pulmonary function test of our patient

\begin{tabular}{lccc}
\hline Parameter of PFT & Before treatment & 2 weeks after treatment & 2 months after treatment \\
\hline FVC\% predicted & 35.7 & 58.7 & 62.9 \\
VC\% predicted & 37.8 & 57.5 & 66.0 \\
TLC\% predicted & 74.3 & 81.6 & - \\
FEV1\% predicted & 36.5 & 52.3 & 53.1 \\
FEV1/FVC\% predicted & 104.4 & 90.6 & 85.3 \\
DLCO\% predicted & 56.3 & 71.9 & - \\
RV\% predicted & 181.9 & 163.3 & - \\
\hline
\end{tabular}

PFT, pulmonary function teste; FVC, forced vital capacity; VC, vital capacity; TLC, total lung capacity; FEV1, forced expiratory volume in 1 second; DLCO, diffusing capacity of the lung for carbon monoxide; RV, residual volume; -, not obtained.

Therefore, the final diagnosis was CD (Paris classification: A1b L1+L4a B1 G1) with pulmonary nodules and arthritis. The PCDAI score was 29.5.

After diagnosis, the patient was given $40 \mathrm{mg} / \mathrm{d}$ methylprednisolone intravenously and exclusive enteral nutrition. After 3 days of treatment, the joint swelling and pain of the child had improved. After 2 weeks of intravenous methylprednisolone and exclusive enteral nutrition, his weight increased by $3 \mathrm{~kg}$, his hemoglobin had improved, and his inflammatory markers had decreased (Table 1). The second CT scan of his lung showed that the nodules were smaller than before. The PFTs results were also ameliorated, with a moderate mixed pulmonary ventilation dysfunction and a slightly decreased pulmonary diffusion function (Table 2). His lung lesions were significantly relieved after the use of prednisone; therefore, after discharge, the patient took prednisone $(30 \mathrm{mg} / \mathrm{d})$ and azathioprine $(75 \mathrm{mg} / \mathrm{d})$ orally and received exclusive enteral nutrition, and the prednisone was gradually reduced to stop being taken within 1.5 months. During the follow-up, we found that his adherence and tolerability were good. After 2 months of treatment, the patient's symptoms had significantly improved. His weight increased by $6 \mathrm{~kg}$, his anemia had disappeared, and his inflammatory markers (Table 1) and chest CT (Figure 2C) also improved. MRI of the knee showed that the joint cavity effusion was less than before. PFTs was also improved (Table 2). The PCDAI score was 5 . After stopping the prednisone treatment, azathioprine was given orally, the follow-up was continued for 2 months, and the symptoms were well-controlled.

All procedures performed in studies involving human participants were in accordance with the ethical standards of the institutional and/or national research committee(s) and with the Helsinki Declaration (as revised in 2013). Written informed consent was obtained from the patient.

\section{Discussion and conclusions}

The pathogenesis of pulmonary lesions in CD is not clear. Similarities in the structures of the intestine and bronchus, as well as their common origin from the primitive foregut, may provide a basis for the development of inflammatory changes in the bronchus in patients with inflammatory bowel disease (IBD) (5). The pulmonary lesions of CD may not be related to CD activity. Pulmonary lesions may occur before, after, or at the same time as a CD diagnosis. Most pulmonary lesions of CD occur after gastrointestinal manifestations. In addition, pulmonary lesions can be found both during the active phase of the disease and during the period of remission $(6,7)$.

To summarize the clinical manifestations, auxiliary examination features, and treatments of CD in children with pulmonary involvement, we reviewed articles that were described in the English language of pulmonary involvement in pediatric patients. The keywords "pediatric", "Crohn's disease", and "pulmonary" were used to retrieve the associated literature from PubMed, and the reference lists of these identified studies were checked. The review identified 22 cases of CD with pulmonary involvement (6-24), which consisted of 10 males and 12 females, and the ratio of males to females was 1:1.2. The clinical manifestations, chest radiological features, and histological manifestations of these cases are summarized in Table 3.

The common respiratory symptoms of CD involving the lungs include cough, tachypnea, and dyspnea. The clinical spectra are wide-ranging, including subclinical 
Table 3 Summary of published literature on pulmonary involvement in children with Crohn's disease

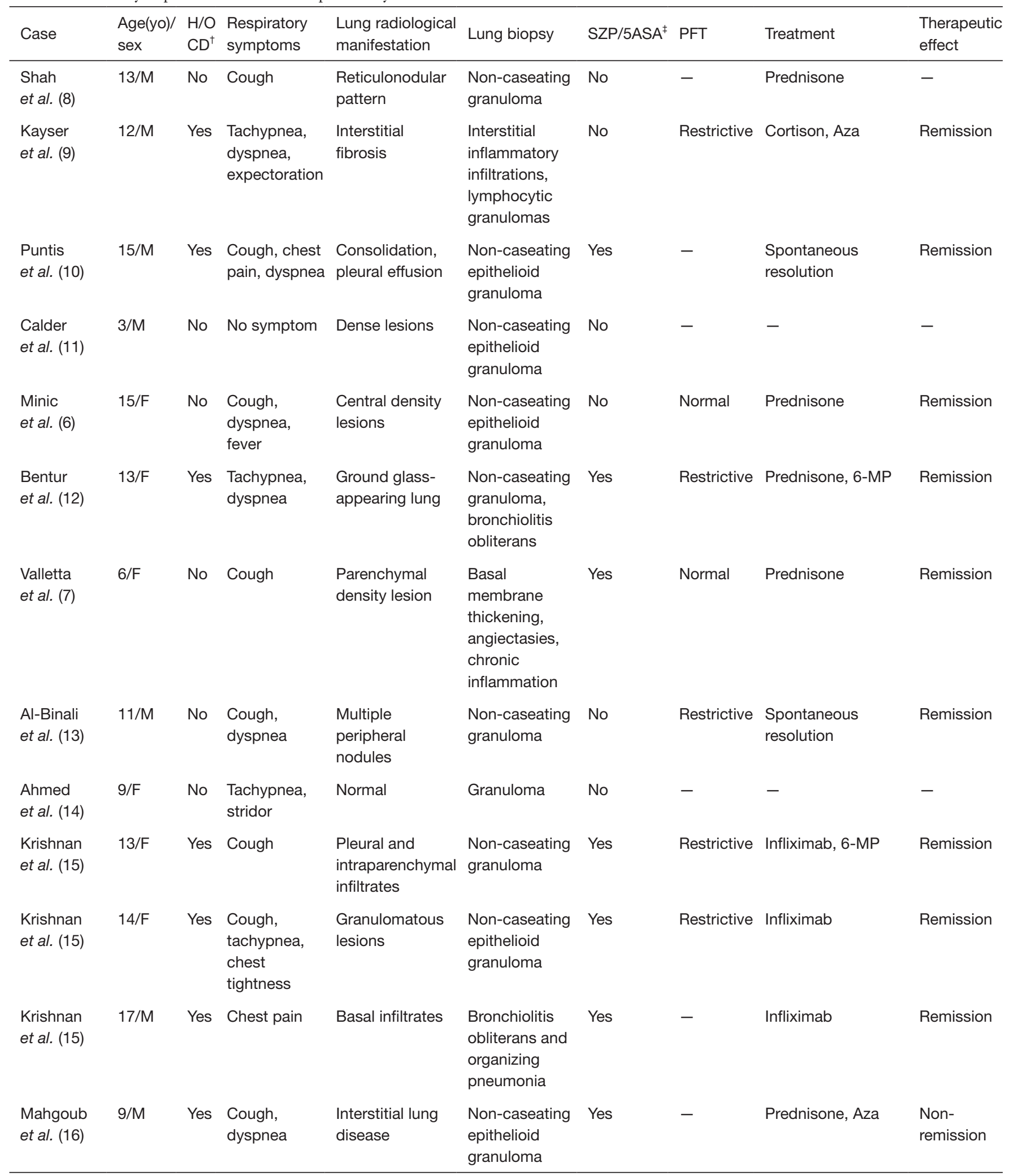

Table 3 (continued) 
Table 3 (continued)

\begin{tabular}{|c|c|c|c|c|c|c|c|c|c|}
\hline Case & $\begin{array}{l}\text { Age(yo)/ } \\
\text { sex }\end{array}$ & $\begin{array}{l}\mathrm{H} / \mathrm{O} \\
\mathrm{CD}^{+}\end{array}$ & $\begin{array}{l}\text { Respiratory } \\
\text { symptoms }\end{array}$ & $\begin{array}{l}\text { Lung radiological } \\
\text { manifestation }\end{array}$ & Lung biopsy & $\mathrm{SZP} / 5 \mathrm{ASA}^{\ddagger}$ & PFT & Treatment & $\begin{array}{l}\text { Therapeutic } \\
\text { effect }\end{array}$ \\
\hline $\begin{array}{l}\text { Levenbrown } \\
\text { et al. (17) }\end{array}$ & $15 / F$ & No & $\begin{array}{l}\text { Cough, } \\
\text { dyspnea }\end{array}$ & $\begin{array}{l}\text { pulmonary } \\
\text { nodules, mass- } \\
\text { like infiltration }\end{array}$ & $\begin{array}{l}\text { Non-caseating } \\
\text { granulomatous } \\
\text { inflammation }\end{array}$ & No & Restrictive & $\begin{array}{l}\text { Methylprednisolone, } \\
\text { MTX }\end{array}$ & Remission \\
\hline $\begin{array}{l}\text { Vadlamudi } \\
\text { et al. (18) }\end{array}$ & $11 / F$ & No & $\begin{array}{l}\text { Cough, } \\
\text { dyspnea }\end{array}$ & $\begin{array}{l}\text { Consolidation } \\
\text { and effusion }\end{array}$ & - & No & - & Steroids, Infliximab & Remission \\
\hline $\begin{array}{l}\text { Chiaro } \\
\text { et al. (19) }\end{array}$ & $14 / F$ & Yes & $\begin{array}{l}\text { Cough, } \\
\text { dyspnea, } \\
\text { wheezing, } \\
\text { chest pain }\end{array}$ & $\begin{array}{l}\text { multiple } \\
\text { pulmonary } \\
\text { nodules, } \\
\text { interstitial } \\
\text { inflammation }\end{array}$ & $\begin{array}{l}\text { Non-caseating } \\
\text { granulomatous } \\
\text { inflammation }\end{array}$ & Yes & - & Steroids & Remission \\
\hline $\begin{array}{l}\text { Darby } \\
\text { et al. (21) }\end{array}$ & $11 / \mathrm{M}$ & No & Cough & $\begin{array}{l}\text { Consolidation, } \\
\text { ground-glass } \\
\text { nodules }\end{array}$ & - & No & - & Infliximab & Remission \\
\hline $\begin{array}{l}\text { Thaver } \\
\text { et al. (22) }\end{array}$ & $5 / F$ & No & No symptom & $\begin{array}{l}\text { Multiple } \\
\text { pulmonary } \\
\text { nodules }\end{array}$ & $\begin{array}{l}\text { Necrotizing } \\
\text { granulomas }\end{array}$ & No & - & Infliximab, MTX & Remission \\
\hline $\begin{array}{l}\text { Ongun } \\
\text { et al. (23) }\end{array}$ & $5 / \mathrm{M}$ & Yes & Tachypnea & $\begin{array}{l}\text { Consolidation, } \\
\text { ground glass } \\
\text { opacities }\end{array}$ & - & No & - & Prednisone & Remission \\
\hline
\end{tabular}

yo, year old; M, male; F, female; SZP, sulfasalazine; 5ASA, 5-aminosalicylic acid; PFT, pulmonary functional test; -, unclear; Aza, azathioprine; 6-MP, 6-mercaptopurine; MTX, methotrexate; ${ }^{\dagger} \mathrm{H} / \mathrm{O} \mathrm{CD}$ while presenting with lung lesion. ${ }^{\ddagger}$ Exposure to SZP or $5 \mathrm{ASA}$ treatment before presentation.

alterations and life-threatening respiratory problems $(11,17,18,23)$. Symptomatic pulmonary disease of CD has rarely been reported in children. Due to the different locations of inflammation, the main manifestations can be diverse. Pulmonary manifestations generally appear after the diagnosis of $\mathrm{CD}$ and are usually aggravated with the recurrence of the disease; however, there are also cases in which pulmonary symptoms can precede gastrointestinal symptoms. In this case, the child was diagnosed with CD after exhibiting anemia, arthritis, and pulmonary abnormalities, while also lacking respiratory symptoms. This is consistent with most literature reports. Further examination of PFTs also confirmed the presence of pulmonary abnormalities in the child.

As many as $37-55 \%$ of patients with IBD have abnormal pulmonary functions or chest radiological features (25). Due to the fact that PFTs abnormalities are frequently found in IBD patients without the presence of any respiratory symptoms (and that these abnormalities persist even after remission), it is assumed that abnormal pulmonary function may be the earliest lung changes in these patients (26). The most common finding of abnormal PFTs in children with IBD is restrictive pulmonary ventilation dysfunction. Decreased diffusion capacity of the lung for 
carbon monoxide (DLCO) is the earliest abnormality that is observed in IBD children with lung involvement, and it is more severe during disease activity than during remission (26). Another study showed that bronchial hyperresponsiveness can occur in children with $\mathrm{CD}$ at a very high proportion ( $71 \%)$, even in the absence of clinical or radiological evidence of pulmonary disease (27). Chest radiological manifestations of $\mathrm{CD}$ are usually nonspecific and can manifest as pulmonary infiltrates, consolidation, nodules, and reticulonodular patterns. The most frequent pulmonary histology of children with CD includes non-caseating granulomatous lesions. Therefore, it is necessary to examine pulmonary function, chest radiology, and histology for children with $\mathrm{CD}$ who are suspected of having pulmonary involvement.

There are many causes of respiratory disease in CD patients, including infectious and noninfectious factors. When considering that most of the medications that are used to treat CD will cause immunosuppression, it is necessary to rule out infection in these patients, especially opportunistic infections such as tuberculosis and fungi. The etiological inspection of this case was negative; thus, we ruled out that his pulmonary nodules were caused by infectious factors. Pulmonary symptoms in patients with $\mathrm{CD}$ may also be caused by side effects of medications, such as sulfasalazine or mesalamine (28). In this case, we did not consider that the pulmonary lesions were caused by medications because no similar medications had been used in the past. Additionally, pulmonary nodules should be distinguished from sarcoidosis, chronic granulomatous diseases, and Wegener's granulation. The histological features of both CD and sarcoidosis are noncaseating granulomas in the involved organs. Clinically, these two diseases are mainly distinguished according to which organs are primarily involved. Sarcoidosis mainly involves the mediastinal lymph nodes and lungs. There are few reports of sarcoidosis involving the gastrointestinal tract (18), whereas CD mainly involves the gastrointestinal tract. Gastroscopic examination of the child showed a bamboo joint-like appearance. A bamboo-joint-like appearance in the gastric body and cardia is thought to be the most representative gastroduodenal endoscopic finding of CD with upper gastrointestinal involvement (29). Iron deficiency anemia is common in CD, and only a few cases of sarcoidosis have been reported in patients who are diagnosed with anemia (13). This case had anemia, which was mainly considered to be caused by CD. Chronic granulomatous disease (30) and Wegener's granuloma (31) can also affect the lungs and gastrointestinal tract, but this scenario is very rare. A large majority of patients with chronic granulomatous disease have a history of chronic or recurrent infections (32). Wegener's granuloma mostly exhibits granulomatous inflammation and necrotizing vasculitis, as well as positive evidence of ANCAs (18). The child in our case had no manifestations of repeated infections, and the ANCAs was negative. Due to the fact that our hospital did not conduct anti-Saccharomyces cerevisiae antibody and fecal calprotectin tests at that time, this patient did not receive these two tests; therefore, there are certain limitations of this case report. Combined with the endoscopic manifestations and pathological results of lung biopsy in the child, the lung nodules in this patient were finally confirmed to be CD lung lesions.

Despite increasing awareness and knowledge about IBD-associated pulmonary disease, little is known about its treatment. Current treatment recommendations are empirical and based upon expert opinions, which mainly emphasizes the use of inhaled or systemic corticosteroids (33) or combinations of drugs, such as mercaptopurine and methotrexate, to better control the symptoms (18). Approximately 2/3 of cases of IBD-related lung disease were treated effectively with glucocorticoid therapy, but approximately $1 / 3$ of patients failed in the course of this treatment, as they did not respond to corticosteroids or could not be tapered off (33). According to previous experience in the treatment of $\mathrm{CD}$, intravenous methylprednisolone or oral prednisone at $1-2 \mathrm{mg} / \mathrm{kg} / \mathrm{d}$ can be used for 2-3 months. For patients who have failed glucocorticoid therapy, infliximab may be another choice for the treatment of IBD with lung disease (15). However, there were also reports of remission without treatment $(10,13)$. We considered that this patient had CD involving the lungs, and the lung lesions were significantly relieved after treatment for $\mathrm{CD}$, which also confirmed the diagnosis.

In summary, the pulmonary manifestations of $\mathrm{CD}$ are rare extraintestinal manifestations that are easily ignored. For children with CD who have respiratory symptoms, chest radiological manifestations, or lung dysfunction, it is necessary to determine whether there is lung involvement. Even if there is no typical intestinal manifestation, if there are various extraintestinal manifestations, such as pulmonary nodules, abnormal pulmonary function, and anemia, the possibility of CD still needs to be considered.

\section{Acknowledgments}

Language was polished by "American Journal Experts" 
(The certificate may be verified at www.aje.com/certificate, Certificate Verification Code: DF3B-BF49-D2B7-250B037F).

Funding: This work was supported by the Scientific Research Fund of Shanghai Municipal Health Commission (201640368).

\section{Footnote}

Reporting Checklist: The authors have completed the CARE reporting checklist. Available at http://dx.doi.org/10.21037/ tp-21-41

Peer Review File: Available at http://dx.doi.org/10.21037/tp21-41

Conflicts of Interest: All authors have completed the ICMJE uniform disclosure form (available at http://dx.doi. org/10.21037/tp-21-41). The authors have no conflicts of interest to declare.

Ethical Statement: The authors are accountable for all aspects of the work in ensuring that questions related to the accuracy or integrity of any part of the work are appropriately investigated and resolved. All procedures performed in studies involving human participants were in accordance with the ethical standards of the institutional and/or national research committee(s) and with the Helsinki Declaration (as revised in 2013). Written informed consent was obtained from the patient.

Open Access Statement: This is an Open Access article distributed in accordance with the Creative Commons Attribution-NonCommercial-NoDerivs 4.0 International License (CC BY-NC-ND 4.0), which permits the noncommercial replication and distribution of the article with the strict proviso that no changes or edits are made and the original work is properly cited (including links to both the formal publication through the relevant DOI and the license). See: https://creativecommons.org/licenses/by-nc-nd/4.0/.

\section{References}

1. Shikhare G, Kugathasan S. Inflammatory bowel disease in children: current trends. J Gastroenterol 2010;45:673-82.

2. Hyams JS. Extraintestinal manifestations of inflammatory bowel disease in children. J Pediatr Gastroenterol Nutr 1994;19:7-21.
3. Kraft SC, Earle RH, Roesler M, et al. Unexplained bronchopulmonary disease with inflammatory bowel disease. Arch Intern Med 1976;136:454-9.

4. Rodgers BH, Clark LM, Kirsner JB. The epidemiologic and demographic characteristics of inflammatory bowel disease: an analysis of a computerized file of 1,400 patients. Chronic Dis 1971;24:743-73.

5. van Lierop PP, Samsom JN, Escher JC, et al. Role of the innate immune system in the pathogenesis of inflammatory bowel disease. J Pediatr Gastroenterol Nutr 2009;48:142-51.

6. Minic P, Perisic VN, Minic A. Metastatic Crohn's disease of the lung. J Pediatr Gastroenterol Nutr 1998;27:338-41.

7. Valletta E, Bertini M, Sette L, et al. Early bronchopulmonary involvement in Crohn disease: a case report. BMC Gastroenterol 2001;1:13.

8. Shah SM, Clinton Texter E, White HJ. Inflammatory bowel disease associated with granulomatous lung disease:report of case with endoscopic findings. Gastrointest Endosc 1976;23:98-9.

9. Kayser K, Probst F, Gabius HJ, et al. Are these characteristic alterations of lung tissue associated with Crohn's disease?. Pathol Res Pract 1990;186:485-90.

10. Puntis JW, Tarlow MJ, Raafat F, et al. Crohn's disease of the lung. Arch Dis Child 1990;65:1270-1.

11. Calder CJ, Lacy D, Raafat F, et al. Crohn's disease with pulmonary involvement in a 3 year old boy. Gut 1993;34:1636-8.

12. Bentur L, Lachter J, Koren I, et al. Severe pulmonary disease in association with Crohn's disease in a 13 year-old girl. Pediatr Pulmonol 2000;29:151-4.

13. Al-Binali AM, Scott B, Al-Garni A, et al. Granulomatous pulmonary disease in a child: an unusual presentation of Crohn's disease. Pediatr Pulmonol 2003;36:76-80.

14. Ahmed KA, Thompson JW, Joyner RE, et al. Airway obstruction secondary to tracheobronchial involvement of asymptomatic undiagnosed Crohn's disease in pediatric patient. Int J Pediatr Otorhinolaryngol 2005;69:1003-5.

15. Krishnan S, Banquet A, Newman L, et al. Lung lesions in children with Crohn's disease presenting as nonresolving pneumonias and response to infliximab therapy. Pediatrics 2006;117:1440-3.

16. Mahgoub LE, Puntis JW, Chetcuti PA, et al. Severe Crohn disease of the lung following colectomy. J Pediatr Gastroenterol Nutr 2007;45:477-9.

17. Levenbrown Y, Tauber D, Hall OR, et al. Granulomatous lung disease as the initial presentation of Crohn's disease. J Pediatr Gastroenterol Nutr 2009;48:487-90. 
18. Vadlamudi NB, Navaneethan U, Thame KA, et al. Crohn's disease with pulmonary manifestations in children: 2 case reports and review of the literature. J Crohns Colitis 2013;7:e85-92.

19. Chiaro A, Fries W, Romano C. Pediatric pulmonary Crohn's disease: More frequent than expected. J Crohns Colitis 2013;7:e189-90.

20. Nelson BA, Kaplan JL, El Saleeby CM, et al. Case records of the Massachusetts General Hospital. Case 39-2014: A 9-Year-Old Girl with Crohn's Disease and Pulmonary Nodules. N Engl J Med 2014;371:2418-27.

21. Darby JB, Rees CA, Bocchini CE, et al. A Case of an 11-year-old With Cough, Diarrhea, and Findings of Concern in His Lungs and Spleen. Pediatrics 2016;137:e20150155.

22. Thaver D, Beg M. Pulmonary Crohn's Disease in Down Syndrome: A Link or Linkage Problem. Case Rep Gastroenterol 2016;10:206-11.

23. Ongun EA, Artan R, Bingol A, et al. A rare aspect of Crohn's disease: Pulmonary involvement in a child. Indian J Crit Care Med 2016;20:114-6.

24. Inoue K, Kusunoki T, Fujii T. Organizing pneumonia as an extraintestinal manifestation of Crohn's disease in a child. Pediatr Pulmonol 2017;52:E64-E66.

25. Massart A, Hunt DP. Pulmonary Manifestations of Inflammatory Bowel Disease. Am J Med 2020;133:39-43.

26. El Amrousy DM, Hassan S, El-Ashry H, et al. Pulmonary Function Tests Abnormalities in Children With Inflammatory Bowel Disease: Is It Common? J Pediatr

Cite this article as: Cao W, Deng X, Xu C, Wang X, Yu Y, Xu $\mathrm{X}, \mathrm{Li}$ J, Xiao Y. Crohn's disease with pulmonary granuloma in a child: a case report and review of the literature. Transl Pediatr 2021;10(6):1728-1736. doi: 10.21037/tp-21-41
Gastroenterol Nutr 2018;67:346-50.

27. Mansi A, Cucchiara S, Greco L, et al. Bronchial hyperresponsiveness in children and adolescents with Crohn's disease. Am J Respir Crit Care Med 2000;161:1051-4.

28. Kohli R, Melin-Aldana H, Sentongo TA. Mesalamineinduced pneumonitis during therapy for chronic inflammatory bowel disease: a pediatric case report. J Pediatr Gastroenterol Nutr 2005;41:479-82.

29. Yokota K, Saito Y, Einami K, et al. A bamboo jointlike appearance of the gastric body and cardia: possible association with Crohn's disease. Gastrointest Endosc 1997;46:268-72.

30. Damen GM, van Krieken JH, Hoppenreijs E, et al. Overlap, common features and essential differences in pediatric granulomatous inflammatory bowel disease. J Pediatr Gastroenterol Nutr 2010;51:690-7.

31. Radhakrishnan KR, Kay M, Wyllie R, et al. Wegener granulomatosis mimicking inflammatory bowel disease in a pediatric patient. J Pediatr Gastroenterol Nutr 2006;43:391-4.

32. Winkelstein JA, Marino MC, Johnston RB Jr, et al. Chronic granulomatous disease: report on a national registry of 368 patients. Medicine (Baltimore) 2000;79:155-69.

33. Hayek AJ, Pfanner TP, White HD. Inflammatory bowel disease of the lung: The role of infliximab? Respir Med Case Rep 2015;15:85-8. 